\title{
Principles of system design not realized for pediatric craniospinal trauma care in the United States
}

\author{
Joseph Piatt, MD, MAS \\ Division of Neurosurgery, Nemours/Alfred I. duPont Hospital for Children, Wilmington, Delaware; and Departments of \\ Neurological Surgery and Pediatrics, Sidney Kimmel Medical College, Thomas Jefferson University, Philadelphia, Pennsylvania
}

OBJECTIVE An implicit expectation of the pioneers of trauma system design was that high clinical volume at select centers could lead to superior outcomes. There has been little study of the regionalization of pediatric craniospinal trauma care, and whether it continues to trend in the direction of regionalization is unknown. The motivating hypothesis for this study was that trauma system design in the United States is proceeding on a rational basis, producing hospital caseloads that are increasing over time and, because of geographic siting appropriate to the needs of catchment areas, in an increasingly uniform manner.

METHODS Data were obtained from the Kids' Inpatient Database (KID) for 1997, 2000, 2003, 2006, 2009, and 2012. Cases of traumatic spinal injury (TSI) and severe traumatic brain injury (STBI) were identified by ICD-9 diagnostic and procedural codes. Records of patients 18 years of age and older were excluded. Hospital caseloads and descriptive statistics were calculated for each year of the study, and trends were examined. The distributions of hospital caseloads were compared year with year and with simulations of idealized systems.

RESULTS Caseloads of TSI trended upward and caseloads of STBI were stable, despite a declining nationwide incidence of these conditions during the study period, so the pool of hospitals providing services for pediatric craniospinal trauma contracted to a degree. The distributions of hospital caseloads did not change, and in every year of the study large numbers of hospitals reported small numbers of discharges. In the last year of the study, a quarter of all children with TSI were discharged from hospitals that treated approximately 1 case or fewer every other month and a quarter of all children with STBI were discharged from hospitals that treated 1 case or fewer every 3 months.

CONCLUSIONS There has been no previous study of nationwide trends in pediatric craniospinal trauma caseloads. Analysis of hospital caseloads from 1997 through 2012 supports inference of a persisting geographical mismatch between population needs and the availability of services. These observations falsify the study hypothesis. A notable fraction of pediatric craniospinal trauma care continues to be rendered at low-caseload institutions. Novel quality assurance methods tailored to the needs of low-caseload institutions deserve development and study.

https://thejns.org/doi/abs/10.3171/2018.1.PEDS17625

KEYWORDS craniospinal trauma; epidemiology; pediatric spinal injury; traumatic brain injury; trauma system

$\mathrm{C}$ ONCENTRATION of the care of victims of trauma at specialized centers improves outcomes. This general principle has been substantiated by numerous case studies of regional and statewide trauma systems since the late 1980s for both adults and children. ${ }^{13,15-17,20,22-24}$ At least 2 factors may be relevant: adherence to accepted protocols that eliminate practice variation has produced better outcomes in the management of severe traumatic brain injury (sTBI), 3,12,19,25 and case volume also has been shown to correlate positively with outcomes for a variety of neurosurgical conditions, ${ }^{4,8,10,11,29}$ including trauma. ${ }^{1}$ Not all geographical locations are served by an organized trauma system, and investigators have raised concerns about the number of children with sTBI who failed to reach verified trauma centers. ${ }^{14,18}$ Furthermore, the openings of trauma centers have not always been matched to the needs of catchment areas. ${ }^{30}$ The degree to which a desirable concentration of cases has actually been achieved on a nation-

ABBREVIATIONS ACS = American College of Surgeons; COT = Committee on Trauma; HCUP = Healthcare Cost and Utilization Project; KID = Kids' Inpatient Database; STBI = severe traumatic brain injury; TSI = traumatic spinal injury.

SUBMITTED November 11, 2017. ACCEPTED January 23, 2018.

INCLUDE WHEN CITING Published online April 20, 2018; DOI: 10.3171/2018.1.PEDS17625. 
wide basis is not known. The motivating hypothesis for this study is that trauma system design in the United States is proceeding on a rational basis, producing hospital caseloads that are increasing over time and, because of geographic siting appropriate to the needs of catchment areas, in an increasingly uniform manner.

\section{Methods}

Data were obtained from the Kids' Inpatient Database (KID) for 1997, 2000, 2003, 2006, 2009, and 2012. The KID is prepared every 3 years by the Healthcare Cost and Utilization Project (HCUP) of the Agency for Healthcare Research and Quality in cooperation with participating states. It is a compilation of de-identified discharge data from a sample of all hospital discharges of patients in the pediatric age range from community, nonrehabilitation hospitals in the United States. Each KID includes approximately $10 \%$ of all discharges of uncomplicated inhospital live births and approximately $80 \%$ of discharges of complicated births and other pediatric cases from each sampled hospital. The KID does not capture emergency department discharges or transfers. Samples are drawn from all hospitals with any pediatric discharges in the participating states. Table 1 presents the states participating in each year of the KID and the number of reporting hospitals with pediatric discharges. The sampling is stratified, and the files are weighted to allow extrapolation of incidences on a nationwide or regional basis or on the basis of several other stratifying factors, but only unweighted data were used for this analysis.

Each admission file incorporates 15 to 25 fields for ICD-9-CM diagnostic codes. In the core data set for each year, the KID includes a code for the discharging hospital as well. Unfortunately, hospital codes varied from year to year of KID publication, so tracking of discharges from individual hospitals through all the years of the study was impossible. The traumatic spinal injury (TSI) data set consists of cases identified by ICD-9 diagnostic codes for spinal fracture without spinal cord injury (805.XX), spinal fracture with spinal cord injury (806.XX), spinal dislocation (839.00-839.59), and spinal cord injury without evidence of spinal osseous injury (952.XX). The accepted clinical definition of severe traumatic brain injury (sTBI) is based on Glasgow Coma Scale scores between 3 and 8, but the KID does not include these scores; therefore, an operational definition of sTBI was adopted consisting of the presence of a head injury code (800.XX, 801.XX, 803. XX, 804.XX, 850.XX, 851.XX, 852.XX, 853.XX, 854. $\mathrm{XX}$ ) in the first field for diagnostic codes, a procedural code for mechanical ventilation (967.0-967.2), and length of stay longer than 3 days. This definition and similar definitions of sTBI have been utilized in past epidemiological studies based on the KID. ${ }^{27,32}$ For TSI and sTBI, year by year, files meeting the case definitions were extracted to create study data sets. These data sets represented nearly complete tallies of TSI and sTBI discharges from reporting states for each year of the study. Discharges of patients 18 years of age or older were excluded. Because the KID is an $80 \%$ sample of all pediatric discharges, there is an $80 \%$ chance that transfers to another acute care facility in the same state are double counted. Discharges ending in transfer to another acute care facility were retained for this study, but they accounted for only $2.25 \%$ of TSI discharges. The study definition of sTBI precluded the possibility of double counting of acute care admissions.

The study hypothesis, that the care of pediatric craniospinal trauma is undergoing regionalization over time in rationally organized trauma systems, has multiple facets

TABLE 1. Summary of KID states and hospitals

\begin{tabular}{|c|c|c|c|c|c|c|}
\hline & \multicolumn{6}{|c|}{ Year } \\
\hline & 2012 & 2009 & 2006 & 2003 & 2000 & 1997 \\
\hline No. of states & 44 & 44 & 38 & 36 & 27 & 22 \\
\hline Data sources & $\begin{array}{c}\text { AK, AR, AZ, CA, CO, } \\
\text { CT, FL, GA, HI, IA, } \\
\text { IL, IN, KS, KY, LA, } \\
\text { MA, MD, MI, MN, } \\
\text { MO, MT, NC, ND, } \\
\text { NE, NJ, NM, NV, } \\
\text { NY, OH, OK, OR, } \\
\text { PA, RI, SC, SD, TN, } \\
\text { TX, UT, VA, VT, WA, } \\
\text { WI, WV, WY (added } \\
\text { AK \& ND; ME \& NH } \\
\text { were not included) }\end{array}$ & $\begin{array}{l}\text { AR, AZ, CA, CO, CT, } \\
\text { FL, GA, HI, IA, IL, } \\
\text { IN, KS, KY, LA, MA, } \\
\text { ME, MD, MI, MN, } \\
\text { MO, MT, NC, NE, } \\
\text { NH, NM, NJ, NV, } \\
\text { NY, OH, OK, OR, } \\
\text { PA, RI, SC, SD, TN, } \\
\text { TX, UT, VA, VT, } \\
\text { WA, WI, WV, WY, } \\
\text { (added LA, ME, MT, } \\
\text { NM, PA, \& WY) }\end{array}$ & $\begin{array}{l}\text { AR, AZ, CA, CO, CT, } \\
\text { FL, GA, HI, IA, IL, } \\
\text { IN, KS, KY, MA, } \\
\text { MD, MI, MN, MO, } \\
\text { NC, NE, NH, NJ, } \\
\text { NV, NY, OH, OK, } \\
\text { OR, RI, SC, SD, } \\
\text { TN, TX, UT, VA, } \\
\text { VT, WA, WI, WV } \\
\text { (added AR \& OK; } \\
\text { ME \& PA were not } \\
\text { included) }\end{array}$ & $\begin{array}{l}\text { AZ, CA, CO, CT, FL, } \\
\text { GA, HI, IA, IL, IN, } \\
\text { KS, KY, MD, MA, } \\
\text { MI, MN, MO, NC, } \\
\text { NE, NH, NJ, NV, NY, } \\
\text { OH, OR, RI, SC, SD, } \\
\text { TN, TX, UT, VA, VT, } \\
\text { WA, WI, WV (added } \\
\text { IL, IN, MI, MN, NE, } \\
\text { NH, NV, OH, RI, SD, } \\
\text { \& VT; ME \& PA were } \\
\text { not included) }\end{array}$ & $\begin{array}{l}\text { AZ, CA, CO, CT, } \\
\text { FL, GA, HI, IA, } \\
\text { KS, KY, MD, } \\
\text { MA, ME, MO, } \\
\text { NC, NJ, NY, } \\
\text { OR, PA, SC, } \\
\text { TN, TX, UT, VA, } \\
\text { WA, WI, WV } \\
\text { (added KY, ME, } \\
\text { NC, TX, VA, \& } \\
\text { WV; IL was not } \\
\text { included) }\end{array}$ & $\begin{array}{c}\text { AZ, CA, CO, } \\
\text { CT, FL, } \\
\text { GA, HI, } \\
\text { IL, IA, KS, } \\
\text { MD, MA, } \\
\text { MO, NJ, } \\
\text { NY, OR, } \\
\text { PA, SC, } \\
\text { TN, UT, } \\
\text { WA, WI }\end{array}$ \\
\hline $\begin{array}{c}\text { No. of hospitals } \\
\text { w/ pediatric } \\
\text { discharges }\end{array}$ & 4,179 & 4,121 & 3,739 & 3,438 & 2,784 & 2,521 \\
\hline $\begin{array}{c}\text { No. of pediatric } \\
\text { discharges }\end{array}$ & $3,195,782$ & $3,407,146$ & $3,131,324$ & $2,984,129$ & $2,516,833$ & $1,905,797$ \\
\hline
\end{tabular}

Adapted from Introduction to the HCUP Kids' Inpatient Database (KID) 2012. Healthcare Cost and Utilization Project (HCUP). 2012. Agency for Healthcare Research and Quality, Rockville, MD. www.hcup-us.ahrq.gov/db/nation/kid/kid_2012_introduction.jsp. Data in the public domain. 


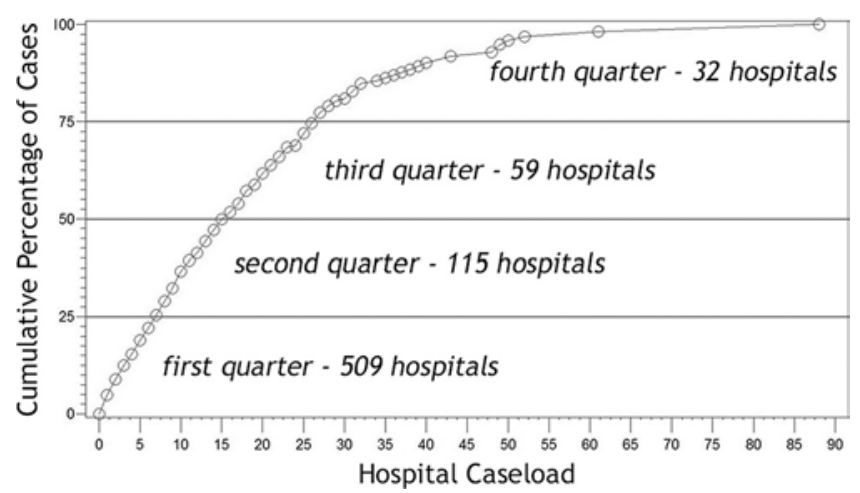

FIG. 1. Construction of tables of quarter hospital counts. Cases were ranked according to the caseload of the hospital from which they were discharged and then divided into quarters. The number of hospitals contributing discharges to each quarter was counted. The data for TSI in 2012 are shown.

that might be addressed by several lines of evidence. Over time, low-caseload hospitals might be expected to drop out, and if annual incidences remained stable, caseloads at the remaining hospitals would increase and caseload variance would decrease. Siting of trauma centers according to the needs of catchment areas would move caseloads toward greater uniformity as well. Therefore, a variety of potentially relevant statistics were developed: Caseloads were tabulated by hospital. Means and coefficients of variation of caseloads were calculated for each year and then correlated with the year of the study using the Pearson $r$. (The coefficient of variation is defined as the ratio of the standard deviation to the mean. It is a dimensionless measure of dispersion of data.) Analysis was conducted excluding the large number of reporting hospitals that had no discharges meeting case definitions. The yearly distributions of discharge counts were compared using the Kruskal-Wallis statistic.

Finally, in order to support analysis of trends in caseload distributions by contingency tables, tables of "quarter hospital counts" were constructed as follows. Cases were ranked according to the caseload of TSI or sTBI discharges at the discharging hospital, and caseload quartiles were calculated. These quartiles divide the ranked cases into quarters (Fig. 1). Counts of hospitals contributing to each quarter of cases were then tabulated by year. Tables of hospital counts were analyzed as contingency tables using the Pearson chi-square statistic. Contingency table analysis of quarter hospital counts was adopted because it obviates difficulties in the study data set arising from trends during the study period in numbers of reporting states and in nationwide TSI and sTBI incidences. To illustrate the interpretation of such data, Fig. 2 compares the actual distribution of caseloads of TSI in 2012 with two hypothetical distributions in idealized trauma systems. The bar graph for the first step of the simulation, which represents the idealized functioning of a system in which each center is prepared identically to provide expert care and is burdened with identical expected caseloads, exhibits greatly reduced hospital counts in the first quarter compared with the actual 2012 distribution and greater counts in the second, third, and fourth quarters. The bar graph for the sec-

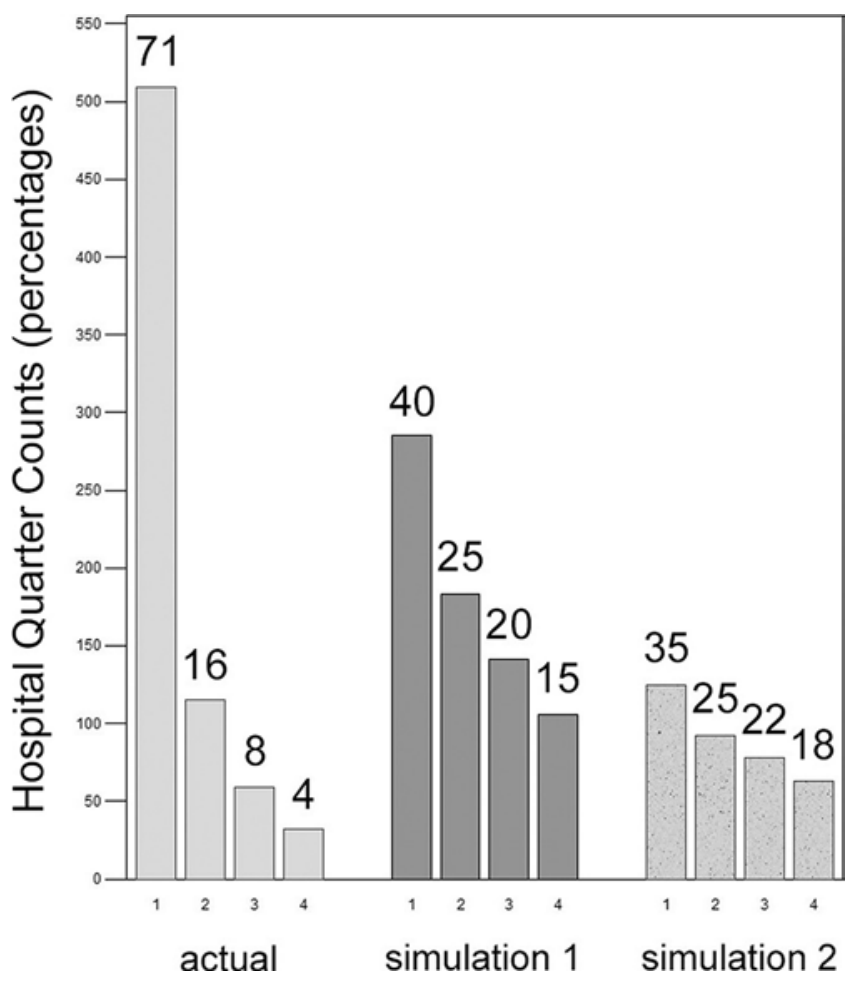

FIG. 2. Actual quarter hospital counts for TSI in 2012 compared with idealized, simulated caseload distributions. The first hypothetical is a simulation of a system in which centers are perfectly sited so that each of the 715 hospitals that reported in 2012 had identical expectations of 6.83 cases, the mean TSI caseload for 2012, according to a Poisson probability distribution. The second hypothetical simulates a more intensely regionalized system in which TSI discharges are shared among half as many reporting hospitals with twice the expected caseload.

ond step of the simulation, which represents the idealized organization of a system designed to concentrate cases at fewer centers to optimize clinical experience, exhibits still more uniformity of quarter counts. Thus, large-scale deliberate design of trauma systems to ensure high and nearly uniform caseloads at hospitals sited according to the needs of catchments, as conceptualized in the motivating hypothesis for this study, would be manifested by a progressive leveling of hospital counts across quarters and progressive diminution of the coefficients of variation.

Data were organized and analyzed using SAS 9.4 (SAS Institute, Inc.). The Nemours Delaware Valley Institutional Review Board judged this project not to be human subjects research.

\section{Results}

\section{Traumatic Spinal Injury}

Table 2 presents the mean hospital TSI caseloads among hospitals that had any TSI discharges and pairwise comparisons of caseload distributions for each year of the study. Over time, fewer hospitals reported TSI discharges, even as the number of participating states and the number of hospitals in the sample frame increased. The consistent increasing trend in TSI caseloads is evident (Pearson $r=$ $0.1041 ; \mathrm{p}<0.0001)$. There was an inconsistent and statisti- 
TABLE 2. TSI discharges from all hospitals with any TSI discharges

\begin{tabular}{rcccccc}
\hline Year & $\begin{array}{c}\text { No. of Hospitals } \\
\text { w/ TSI Discharges }\end{array}$ & $\begin{array}{c}\text { Total TSI } \\
\text { Discharges }\end{array}$ & $\begin{array}{c}\text { Mean Hospital } \\
\text { TSI Caseload }\end{array}$ & $\begin{array}{c}\text { Hospital TSI Caseload } \\
\text { Coefficient of Variation }\end{array}$ & $\begin{array}{c}\text { Hospital TSI } \\
\text { Caseload Range }\end{array}$ & $\begin{array}{c}\text { Kruskal-Wallis Comparisons of Count } \\
\text { Distributions (Bonferroni corrections) }\end{array}$ \\
\hline 1997 & 958 & 4283 & 4.47 & 1.49 & 1 to 71 & A \\
\hline 2000 & 757 & 3688 & 4.87 & 1.39 & 1 to 57 & A, B \\
\hline 2003 & 872 & 4772 & 5.47 & 1.45 & 1 to 74 & A, B, C \\
\hline 2006 & 856 & 5488 & 6.41 & 1.54 & 1 to 91 & B, C, D \\
\hline 2009 & 803 & 5302 & 6.60 & 1.43 & 1 to 99 & C, D \\
\hline 2012 & 715 & 4880 & 6.83 & 1.36 & 1 to 88 & D \\
\hline
\end{tabular}

* Years that do not share a letter are significantly different after controlling for multiple comparisons.

cally insignificant downward trend in caseload coefficients of variation (Pearson $r=-0.3584 ; p=0.4854$ ). The yearly distributions of caseloads were different as analyzed by the Kruskal-Wallis test $\left(\chi^{2}=51.41 ; \mathrm{df}=5 ; \mathrm{p}<0.0001\right)$, and many pairwise differences were significant as well.

The distributions of TSI quarter hospital counts are depicted for each year of the study in Fig. 3. A very large number of hospitals reported small numbers of TSI discharges, and a small number of hospitals reported moderately large numbers of discharges. There were no grossly evident or statistically significant trends in the distribution of caseloads over time (Pearson $\chi^{2}=7.1189$; $\mathrm{df}=15 ; \mathrm{p}$ $=0.9543$ ). Quartiles of hospital caseloads of the ranked cases of TSI are presented by year in the second column of Table 3. First quartiles, medians, and third quartiles peaked in 2006 but exhibited a generally increasing trend over the course of the study period.

\section{Severe Traumatic Brain Injury}

Table 4 presents the mean hospital sTBI caseloads among hospitals that had any sTBI discharges and pairwise comparisons of caseload distributions for each year of the study. Unlike TSI, for sTBI there were no clear temporal trends in numbers of reporting hospitals or hospital caseloads (Pearson $r=-0.009$ for caseloads; $p=0.6578$ ). There was a consistent downward trend in caseload coefficients of variation (Pearson $r=-0.8562 ; p=0.0295$ ). The yearly distributions of caseloads were different as analyzed by the Kruskal-Wallis test $\left(\chi^{2}=13.53\right.$; $\mathrm{df}=5 ; \mathrm{p}$

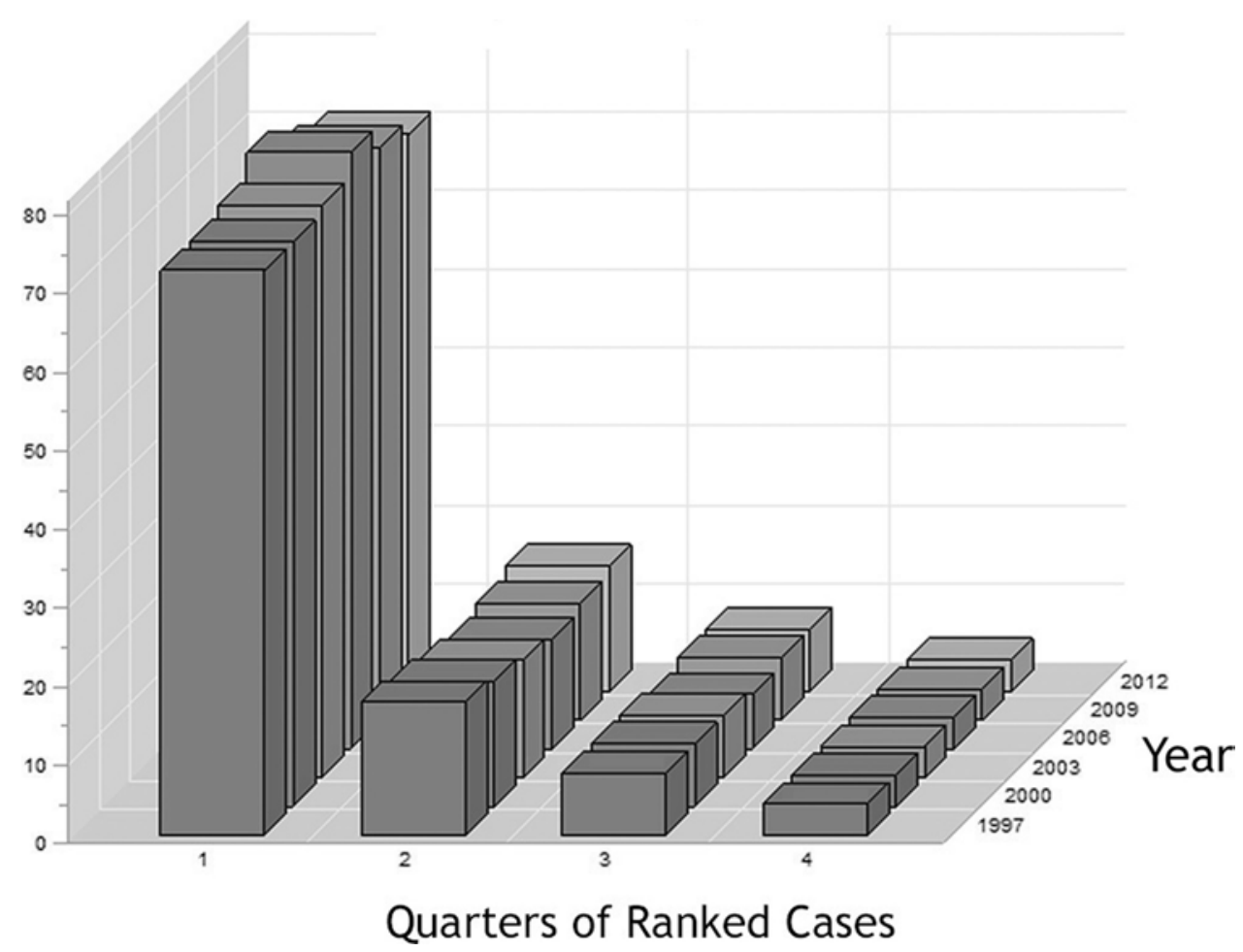

FIG. 3. TSI quarter hospital counts. Cases of TSI have been ranked by caseload of the discharging hospital, and caseload quartiles have been defined. The number of hospitals accounting for each quarter of ranked cases have been counted. The annual percentages of hospitals accounting for each quarter are charted. There is no association of year and quarter hospital count (Pearson $\chi^{2}$ test $=7.1189 ; \mathrm{df}=15 ; p=0.9543$ ). 
TABLE 3. Median of hospital caseloads among ranked cases for TSI and STBI by year*

\begin{tabular}{ccc}
\hline & \multicolumn{2}{c}{ Median (IQR) } \\
\cline { 2 - 3 } Year & TSI & sTBI \\
\hline 1997 & $11(4-20)$ & $10(4-19)$ \\
\hline 2000 & $13(5-20)$ & $10(5-16)$ \\
\hline 2003 & $13.5(6-24)$ & $10(5-16)$ \\
\hline 2006 & $19(7-29)$ & $10(5-16)$ \\
\hline 2009 & $16(8-29)$ & $9(4-13)$ \\
\hline 2012 & $16(7-27)$ & $9(4-13)$ \\
\hline
\end{tabular}

* For example, one-quarter of all cases of TSI were discharged from hospitals that treated 7 or fewer cases. An increasing trend was evident for TSI, but sTBI was stable throughout the study period.

$<0.0189)$. After Bonferroni correction, the only pairwise difference in caseload distributions by the Kruskal-Wallis test was between 1997 and 2006.

The distributions of sTBI quarter hospital counts are depicted for each year of the study in Fig. 4. Like TSI there were no grossly evident or statistically significant trends in the distribution of caseloads over time analyzed by quarter counts (Pearson $\chi^{2}=3.9717$; df $=15 ; \mathrm{p}=0.9978$ ). Quartiles of hospital caseloads of ranked cases of sTBI are presented by year in the third column of Table 3. There was no trend in quartiles of hospital caseloads of sTBI.

\section{Discussion}

The goal of this investigation was to document nationwide trends in the distribution of hospital caseloads of pediatric craniospinal trauma. The data source was not ideally suited to this purpose, and the incidences of the phenomena themselves trended during the study period. To draw conclusions from the data requires consideration of both issues. The cases of TSI and sTBI analyzed in this study were collected in a 2 -stage sampling process. The first stage was a sampling of states. This stage was not scientific; whether states did or did not submit data to the HCUP in each year of the study was the result of administrative and political processes about which nothing is known. As shown in Table 1, not all states participated, and the number of participating states increased from 22 in 1997 to 44 in 2012. The second stage was a random $80 \%$ sample of pediatric discharges from every hospital that had any pediatric discharges. Thus, the study captured nearly all discharges of TSI and STBI in the pediatric age range from participating states with no distinction between trauma centers and other facilities. The findings of this study must be considered in the context of slowly declining population-based incidences of TSI and sTBI in the United States over the years of the study period. Estimated nationwide discharges for TSI fell from 14.18 per 100,000 in 1997 to 9.57 per 100,000 in 2012. ${ }^{26}$ Discharges for sTBI fell from 8.11 per 100,000 in 1997 to 5.58 per 100,000 in $2009 .{ }^{27}$

\section{Traumatic Spinal Injury}

The current study presents a complex picture of the distribution of TSI caseloads. Despite a marked expansion of the participation of states in the KID over the course of the study, the number of hospitals reporting pediatric TSI discharges actually fell. While overall nationwide incidences of TSI fell during the study period, the mean caseload at hospitals reporting TSI discharges increased. Caseload quartiles of ranked cases increased steadily as well. By these metrics the care of pediatric TSI grew more concentrated at a contracting number of institutions. From these observations can be inferred some attrition of hospitals from pediatric TSI care, and the departing hospitals must have had lower caseloads in the aggregate than the hospitals that remained. These inferences are consistent with the study hypothesis. There was no comparable trend in caseload coefficients of variation. This observation is consistent with persistence of widely varying caseloads among hospitals admitting pediatric TSI. The distribution of caseloads was analyzed by the Kruskal-Wallis test. The null hypothesis of the Kruskal-Wallis test is that the test classes have the same distributions of observations. These tests can be sensitive to differences in the shapes of distributions or to left-right translations. The observed increase in mean TSI caseloads over time can account for the rejection of the null without implications regarding the shapes of the distributions. Tabulation of quarter hospital counts is a more specific depiction of the shapes of caseload distributions, and by this analysis there was no large-scale, preferential disappearance of low-caseload hospitals during the study period. In summary the study epoch exhibited a degree of concentration of TSI caseloads, but even in the last year of the study, a quarter of all children with TSI were discharged from hospitals that treated approximately 1 case or fewer every other month.

TABLE 4. sTBI discharges from all hospitals with any sTBI discharges

\begin{tabular}{ccccccc}
\hline Year & $\begin{array}{c}\text { No. of Hospitals w/ } \\
\text { sTBI Discharges }\end{array}$ & $\begin{array}{c}\text { Total sTBI } \\
\text { Discharges }\end{array}$ & $\begin{array}{c}\text { Mean Hospital } \\
\text { sTBI Caseload }\end{array}$ & $\begin{array}{c}\text { Hospital sTBI Caseload } \\
\text { Coefficient of Variation }\end{array}$ & $\begin{array}{c}\text { Hospital sTBI } \\
\text { Caseload Range }\end{array}$ & $\begin{array}{c}\text { Kruskal-Wallis Comparisons of Count } \\
\text { Distributions (Bonferroni corrections) }\end{array}$ \\
\hline 1997 & 335 & 1605 & 4.79 & 1.22 & $1-35$ & $\mathrm{~A}$ \\
\hline 2000 & 334 & 1725 & 5.16 & 1.10 & $1-31$ & $\mathrm{~A}, \mathrm{~B}$ \\
\hline 2003 & 401 & 2112 & 5.27 & 1.17 & $1-56$ & $\mathrm{~A}, \mathrm{~B}$ \\
\hline 2006 & 357 & 2087 & 5.85 & 1.12 & $1-51$ & $\mathrm{~B}$ \\
\hline 2009 & 377 & 1841 & 4.88 & 1.04 & $1-43$ & $\mathrm{~A}, \mathrm{~B}$ \\
\hline 2012 & 384 & 1797 & 4.68 & 1.03 & $1-33$ & $\mathrm{~A}, \mathrm{~B}$ \\
\hline
\end{tabular}

* Years that do not share a letter are significantly different after controlling for multiple comparisons. 


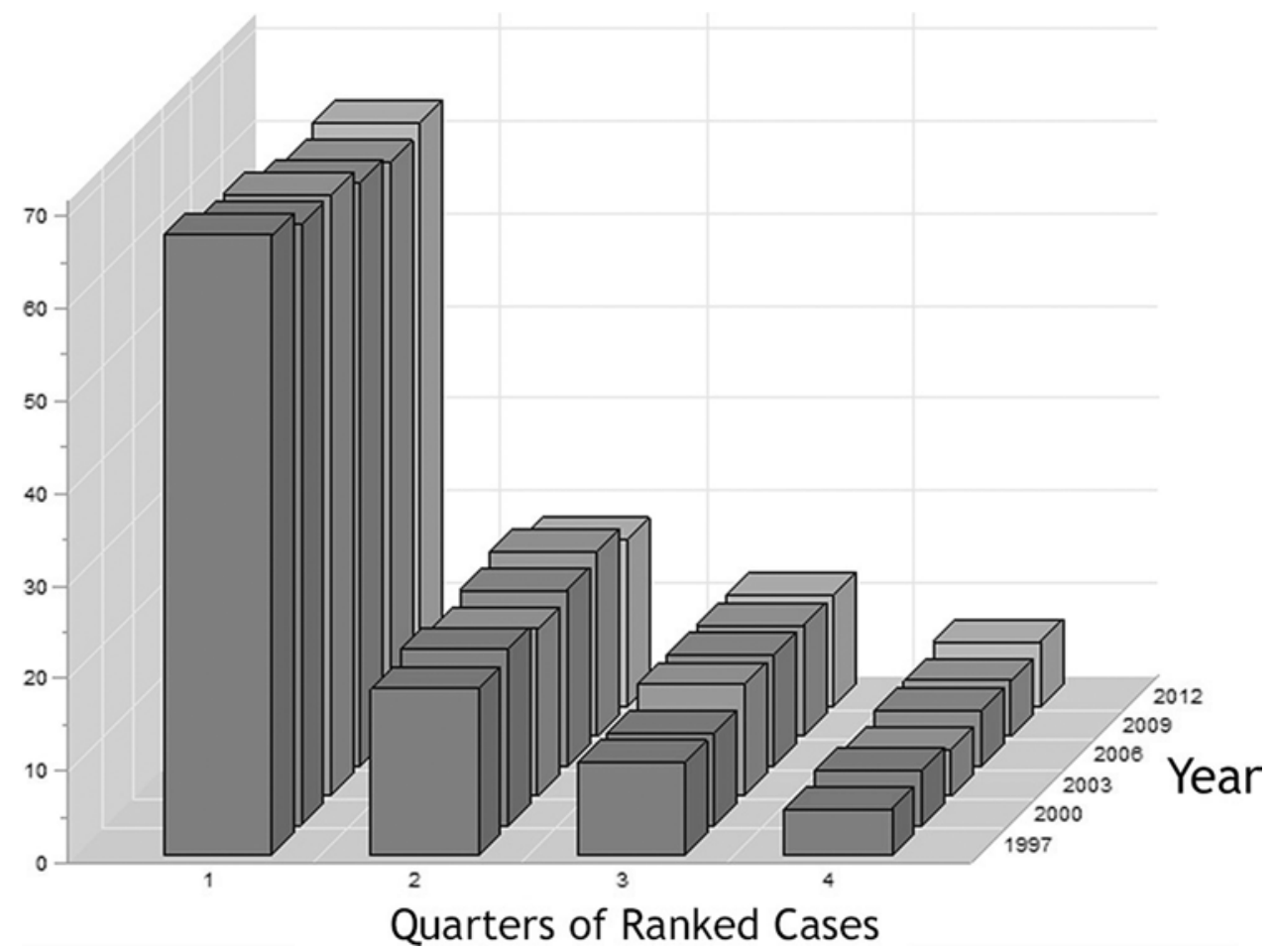

FIG. 4. sTBI quarter hospital counts. Cases of sTBI have been ranked by caseload of the discharging hospital, and caseload quartiles have been defined. The number of hospitals accounting for each quarter of ranked cases have been counted. The annual percentages of hospitals accounting for each quarter are charted. There is no association of year and quarter hospital count (Pearson $\chi^{2}$ test $=3.9717 ; d f=15 ; p=0.9978$ ).

\section{Severe Traumatic Brain Injury}

The picture of sTBI caseload distributions is different but likewise complex. There was no trend in the number of hospitals reporting sTBI in the data sets, but as the number of participating states and the number of hospitals in the KID sample frame increased year by year, the absence of any trend is evidence of concentration of care consistent with the study hypothesis. There was no trend in mean sTBI caseload, and caseload quartiles of ranked cases were stable as well; so the diminishing nationwide incidence of sTBI may have balanced the contraction of the pool of hospitals reporting sTBI discharges. The caseload coefficients of variation fell from 1.22 in 1997 to 1.03 in 2012. For context, the coefficient of variation for an idealized system in which each center had an annual caseload of 4.68 (the mean caseload in 2012) would have been 0.46 . The coefficient of variation for a system with half as many centers and twice the mean caseload would have been 0.33. The downward trend in caseload coefficients of variation is consistent with increasing uniformity of caseloads, but the movement of this statistic was small in comparison with idealized systems. The hospital caseload distributions in 1997 and 2006 differed by the Kruskal-Wallis test, but this analysis suggested no trend. Tabulation of quarter hospital counts provided no evidence of large-scale, preferential disappearance of low-caseload hospitals during the study period. In summary the study epoch exhibited stable sTBI caseloads in the face of falling sTBI incidence and falling numbers of discharging hospitals nationwide. The care of pediatric sTBI seems to have become concentrated at a smaller number of hospitals; nevertheless, throughout the study period a quarter of all children with sTBI were discharged from hospitals that treated 1 case or fewer every 3 months.

During the study period, caseloads increased for TSI but not for sTBI, despite falling nationwide incidences of both conditions. The explanation for this discrepancy may lie in the breadth of the case definitions. The definition of TSI included many relatively minor injuries-fractures that did not destabilize the spine, cause functional disability, or require intensive care unit admission or surgical treatment. The definition of sTBI on the other hand was limited to injuries that were expected to have required intensive, multidisciplinary care. The data suggest that some hospitals with limited resources for trauma care were admitting simpler spinal injuries in 1997 but had abandoned that practice by 2012 . There was no similar trend for STBI. If the definition of TSI had been restricted to spinal cord injury, there might have been no discrepancy, but this analysis was not performed.

An implicit expectation of the pioneers of trauma system design was that high clinical volume at select centers could lead to superior outcomes. The expectation that volume is associated with quality has become explicit in the past decade in many surgical disciplines, including neurosurgery, but what is true for surgery is not necessarily true for trauma, which requires coordinated multidisciplinary care punctuated in only limited instances by technically challenging surgical procedures. A meta-analysis of the association of trauma mortality and hospital volume re- 
ported inconsistent findings and substantial heterogeneity among the small number of reports suitable for analysis. ${ }^{7}$ A recent and sophisticated study of registry data from the National Trauma Data Bank concluded that increasing institutional trauma volume was associated with diminishing rates of risk-adjusted mortality. ${ }^{6}$ Interestingly, several consecutive years of increasing volume were required to produce a measurable improvement. There have been few investigations of hospital volume specific to outcomes of severe TBI. Wada et al. found no association between hospital volume and mortality in a nationwide study in Japan, but the definition of low caseload as $\leq 60$ admissions per year suggests a high degree of existing regionalization. ${ }^{34}$ In a study of Florida trauma centers, Tepas et al. observed associations of risk-adjusted mortality both with hospital sTBI volume and with sTBI as a fraction of total severe trauma volume. ${ }^{31}$ Working with data from the American College of Surgeons (ACS) Trauma Quality Improvement Program registry, Alali et al. demonstrated a strong association between hospital volume and in-hospital mortality for sTBI among adults. ${ }^{1}$ There was no association with complications or mortality after complications. Thus, the association of volume and mortality in trauma care seems to have a different basis from purely surgical conditions, where the association extends to mortality after major complications, or so-called "failure to rescue." The author has found no reports concerning caseload and outcomes of pediatric craniospinal trauma, but data from 2001 reported by Hartman and colleagues indicate that as many as one-third of children with STBI receive care outside of designated trauma centers. ${ }^{14,18}$

The 15-year epoch of the current study must be placed in the historical arc of civilian trauma care in the United States. From the standpoint of public policy and organization of systems of care, the mid-1960s were a time of beginnings. They saw the nearly contemporaneous openings of groundbreaking shock trauma units in Chicago, San Francisco, and Baltimore and the publication of Accidental Death and Disability: The Neglected Disease of Modern Society by the National Academy of Sciences. ${ }^{9,21,33}$ This document moved the public health challenge of trauma into the political spotlight and had many farreaching effects, including the formation of the National Traffic Safety Board. Among its many recommendations was a call for external accreditation of hospitals and systems that provide trauma services, a mission subsequently undertaken by the ACS. Illinois, Maryland, and Florida were early organizers of regional trauma systems in the 1970s. Over the next 2 decades, criteria for model trauma system design came into focus, and trauma systems proliferated with intermittent periods of federal support, so that by 1998 Bazzoli reported that 35 states had met or were in the process of meeting standards. ${ }^{5,33}$ Of importance in the context of the current report, a common system deficiency has been failure to limit the number of trauma centers serving the same region. ${ }^{2,30,33}$ Verification of trauma centers has been based on fulfillment of criteria without regard to regional trauma epidemiology. Verifying authorities, such as the ACS, have required compliance with best practices, but they have not attempted to impose discipline on the geographical distribution of centers. Although the system in the author's state was organized as late as 2000 , the rate of appearance of new statewide or regional systems has probably slowed in the first decade of the current century. The epoch represented in the current study may have been too late to capture dramatic evolutionary effects of trauma system organization on caseload distribution. For the same reason, in the absence of any unforeseeable federal regulatory and funding initiatives, the findings in the current report are likely to remain valid through an indefinite future.

The current study compared pediatric craniospinal hospital caseloads in the United States in the first decade of the 21st century with an ideal world in which patients receive care at institutions located in harmony with the needs of populations. A discrepancy was demonstrated. Although caseloads were stable or increasing in the face of falling nationwide incidences, wide variation in hospital caseloads persisted essentially unchanged through the study period. From the static and highly skewed distributions of hospital quarter counts can be inferred a persisting geographical mismatch between population needs and the availability of services. The ACS Committee on Trauma (COT) has recognized this mismatch and the frequent failure of governmental agencies to address it. ${ }^{2}$ As enforcement of minimum acceptable caseloads does not seem possible in the contemporary marketplace of medicine under its existing regulatory structure, other tools must be employed to assure quality. The Trauma Quality Improvement Program of the ACS COT addresses the general need, ${ }^{28}$ but as they do not seem to be going away, novel quality assurance measures tailored to the needs of low-volume providers deserve development and study.

\section{Limitations}

The limitations of administrative data sets are a topic of frequent comment. The accuracy of diagnostic coding in the KID cannot be confirmed, but unless coding accuracy evolved nationwide in a consistent direction during the course of the study period, it is not an issue for this analysis. Administrative data sets typically have little clinical information, and indeed this limitation necessitated an empirical, nonstandard study definition for sTBI. Once again, unless coding practices evolved in a systematic way during the course of this study, the incongruity between the accepted clinical definition of sTBI and the empirical definition employed in this study is unlikely to have distorted the study findings. Whether the sampling methods employed in the compilation of the KID introduce bias that might affect this analysis is another question. States' policy decisions over time to report or not to report data to the HCUP may have related in some obscure but systematic way to the degree of concentration of pediatric trauma in those states. This potential source of bias is impossible to dismiss, but even in 1997, the first year of the publication of the KID and the year with the smallest selection of participating states, the mix of coastal and central, northern and southern, and urban and rural states is not unrepresentative of the country in any obvious way. Nor is there any obvious mechanism for bias in state participation to produce the consistent observations demonstrated in this study. Finally, the motivating hypothesis of this study was 
based on the general statistical association between caseload and various quality metrics. No aspect of quality was measured in this study, and no finding of this study can be construed to imply that appropriate care cannot be rendered at low-caseload institutions.

\section{Conclusions}

There has been no previous study of nationwide trends in pediatric craniospinal trauma caseloads. Between 1997 and 2012 caseloads of pediatric TSI increased, and caseloads of sTBI remained stable in the face of falling nationwide incidences. These observations imply a degree of concentration of cases during the study period. Nevertheless, the shapes of the distributions of quarter counts of hospitals did not change either for TSI or for sTBI, and from these observations can be inferred a persisting geographical mismatch between population needs and the availability of services. These observations falsify the study hypothesis that trauma system design is proceeding on a rational basis. A notable fraction of pediatric craniospinal trauma care continues to be rendered at low-caseload institutions. Novel quality assurance methods tailored to the needs of low-caseload institutions deserve development and study.

\section{Acknowledgments}

The author gratefully acknowledges useful conversations with Richard J. Mullins, MD.

\section{References}

1. Alali AS, Gomez D, McCredie V, Mainprize TG, Nathens AB: Understanding hospital volume-outcome relationship in severe traumatic brain injury. Neurosurgery 80:534-542, 2017

2. American College of Surgeons Committee on Trauma: Statement on trauma center designation based upon system need. Bull Am Coll Surg 100:51-52, 2015

3. Arabi YM, Haddad S, Tamim HM, Al-Dawood A, AlQahtani S, Ferayan A, et al: Mortality reduction after implementing a clinical practice guidelines-based management protocol for severe traumatic brain injury. J Crit Care 25:190-195, 2010

4. Barker FG II, Amin-Hanjani S, Butler WE, Ogilvy CS, Carter BS: In-hospital mortality and morbidity after surgical treatment of unruptured intracranial aneurysms in the United States, 1996-2000: the effect of hospital and surgeon volume. Neurosurgery 52:995-1009, 2003

5. Bazzoli GJ: Community-based trauma system development: key barriers and facilitating factors. J Trauma 47 (3 Suppl):S22-S24, 1999

6. Brown JB, Rosengart MR, Kahn JM, Mohan D, Zuckerbraun BS, Billiar TR, et al: Impact of volume change over time on trauma mortality in the United States. Ann Surg 266:173178, 2017

7. Caputo LM, Salottolo KM, Slone DS, Mains CW, Bar-Or $\mathrm{D}$ : The relationship between patient volume and mortality in American trauma centres: a systematic review of the evidence. Injury 45:478-486, 2014

8. Cochrane DD, Kestle J: Ventricular shunting for hydrocephalus in children: patients, procedures, surgeons and institutions in English Canada, 1989-2001. Eur J Pediatr Surg 12 (Suppl 1):S6-S11, 2002

9. Committee on Trauma and Committee on Shock:
Accidental Death and Disability: The Neglected

Disease of Modern Society. Washington, DC: National Academy of Sciences, 1966 (https://www.ems.gov/pdf/1997Reproduction-AccidentalDeathDissability.pdf) [Accessed February 15, 2018]

10. Cowan JA Jr, Dimick JB, Leveque JC, Thompson BG, Upchurch GR Jr, Hoff JT: The impact of provider volume on mortality after intracranial tumor resection. Neurosurgery 52:48-54, 2003

11. Curry WT, McDermott MW, Carter BS, Barker FG II: Craniotomy for meningioma in the United States between 1988 and 2000: decreasing rate of mortality and the effect of provider caseload. J Neurosurg 102:977-986, 2005

12. Fakhry SM, Trask AL, Waller MA, Watts DD: Management of brain-injured patients by an evidence-based medicine protocol improves outcomes and decreases hospital charges. J Trauma 56:492-500, 2004

13. Härtl R, Gerber LM, Iacono L, Ni Q, Lyons K, Ghajar J: Direct transport within an organized state trauma system reduces mortality in patients with severe traumatic brain injury. J Trauma 60:1250-1256, 2006

14. Hartman M, Watson RS, Linde-Zwirble W, Clermont G, Lave J, Weissfeld L, et al: Pediatric traumatic brain injury is inconsistently regionalized in the United States. Pediatrics 122:e172-e180, 2008

15. Hulka F, Mullins RJ, Mann NC, Hedges JR, Rowland D, Worrall WH, et al: Influence of a statewide trauma system on pediatric hospitalization and outcome. J Trauma 42:514519,1997

16. Janssens L, Holtslag HR, van Beeck EF, Leenen LP: The effects of regionalization of pediatric trauma care in the Netherlands: a surveillance-based before-after study. J Trauma Acute Care Surg 73:1284-1287, 2012

17. Kelly ML, Banerjee A, Nowak M, Steinmetz M, Claridge JA: Decreased mortality in traumatic brain injury following regionalization across hospital systems. J Trauma Acute Care Surg 78:715-720, 2015

18. Kernic MA, Rivara FP, Zatzick DF, Bell MJ, Wainwright MS, Groner JI, et al: Triage of children with moderate and severe traumatic brain injury to trauma centers. J Neurotrauma 30:1129-1136, 2013

19. Kesinger MR, Nagy LR, Sequeira DJ, Charry JD, Puyana JC, Rubiano AM: A standardized trauma care protocol decreased in-hospital mortality of patients with severe traumatic brain injury at a teaching hospital in a middle-income country. Injury 45:1350-1354, 2014

20. Mann NC, Mullins RJ, MacKenzie EJ, Jurkovich GJ, Mock $\mathrm{CN}$ : Systematic review of published evidence regarding trauma system effectiveness. J Trauma 47 (3 Suppl):S25-S33, 1999

21. Mullins RJ: A historical perspective of trauma system development in the United States. J Trauma 47 (3 Suppl):S8-S14, 1999

22. Mullins RJ, Mann NC, Hedges JR, Worrall W, Jurkovich GJ: Preferential benefit of implementation of a statewide trauma system in one of two adjacent states. J Trauma 44:609-617, 1998

23. Newgard CD, McConnell KJ, Hedges JR, Mullins RJ: The benefit of higher level of care transfer of injured patients from nontertiary hospital emergency departments. J Trauma 63:965-971, 2007

24. Nirula R, Maier R, Moore E, Sperry J, Gentilello L: Scoop and run to the trauma center or stay and play at the local hospital: hospital transfer's effect on mortality. J Trauma 69:595-601, 2010

25. O'Lynnger TM, Shannon CN, Le TM, Greeno A, Chung D, Lamb FS, et al: Standardizing ICU management of pediatric traumatic brain injury is associated with improved outcomes at discharge. J Neurosurg Pediatr 17:19-26, 2016 
26. Piatt J, Imperato N: Epidemiology of spinal injury in childhood and adolescence in the United States: 1997-2012. J Neurosurg Pediatrics [epub ahead of print February 16, 2018; DOI: 10.3171/2017.10.PEDS17530]

27. Piatt JH Jr, Neff DA: Hospital care of childhood traumatic brain injury in the United States, 1997-2009: a neurosurgical perspective. J Neurosurg Pediatr 10:257-267, 2012

28. Shafi S, Nathens AB, Cryer HG, Hemmila MR, Pasquale MD, Clark DE, et al: The Trauma Quality Improvement Program of the American College of Surgeons Committee on Trauma. J Am Coll Surg 209:521-530, 530.e1, 2009

29. Smith ER, Butler WE, Barker FG II: Craniotomy for resection of pediatric brain tumors in the United States, 1988 to 2000: effects of provider caseloads and progressive centralization and specialization of care. Neurosurgery 54:553565,2004

30. Tepas JJ III, Kerwin AJ, Ra JH: Unregulated proliferation of trauma centers undermines cost efficiency of populationbased injury control. J Trauma Acute Care Surg 76:576581,2014

31. Tepas JJ III, Pracht EE, Orban BL, Flint LM: High-volume trauma centers have better outcomes treating traumatic brain injury. J Trauma Acute Care Surg 74:143-148, 2013

32. Tilford JM, Aitken ME, Anand KJ, Green JW, Goodman AC, Parker JG, et al: Hospitalizations for critically ill children with traumatic brain injuries: a longitudinal analysis. Crit Care Med 33:2074-2081, 2005
33. Trunkey DD: History and development of trauma care in the United States. Clin Orthop Relat Res (374):36-46, 2000

34. Wada T, Yasunaga H, Doi K, Matsui H, Fushimi K, Kitsuta Y, et al: Relationship between hospital volume and outcomes in patients with traumatic brain injury: a retrospective observational study using a national inpatient database in Japan. Injury 48:1423-1431, 2017

\section{Disclosures}

The author reports no conflict of interest concerning the materials or methods used in this study or the findings specified in this paper.

\section{Supplemental Information}

\section{Previous Presentations}

This report was presented in part as a poster at the 46th Annual Meeting of the AANS/CNS Section on Pediatric Neurological Surgery in Houston, Texas, on November 30, 2017.

\section{Correspondence}

Joseph Piatt: Nemours/Alfred I. duPont Hospital for Children, Wilmington, DE.jpiatt@nemours.org. 